\title{
Molecular interactions of selected amino acids in aqueous resorcinol solutions: volumetric, viscometric and acoustic studies
}

\author{
Mahendra Nath Roy ${ }^{*}$, Arijit Bhattacharjee and Riju Chanda \\ Department of Chemistry, North Bengal University, Darjeeling-734 013, India \\ mahendraroy2002@yahoo.co.in
}

Abstract: Apparent molar volumes, $V_{\phi}$, viscosities, $\eta$, and apparent molal isentropic compressibility, $K_{\phi}$, of glycine, L-alanine, L-valine and L-leucine in $0.05,0.10,0.15 \mathrm{~mol} \mathrm{~kg}^{-1}$ resorcinol solutions have been determined at $298.15 \mathrm{~K}$ by measuring the densities, viscosities and ultrasonic speed of the above solutions respectively. The apparent molar volumes at infinite dilution, $V_{\phi}^{0}$, standard volumes of transfer, $\Delta_{t r} V_{\phi}^{0}$, apparent molar isentropic compressibilities, $K_{\phi}^{0}$, transfer compressibilities, $\Delta_{t r} K_{\phi}^{0}$, hydration number, $N_{w}$, of the amino acids have been calculated for investigating the various interactions in the ternary solutions. The linear correlation of partial molar volume and viscosity $B$ coefficients with increasing number of carbon atoms in the alkyl chain have been utilized to calculate the contributions of charged end groups $\left(\mathrm{NH}_{3}{ }^{+}, \mathrm{COO}^{-}\right), \mathrm{CH}_{2}$ - groups and other alkyl chains of amino acids to $V_{\phi}^{0}$. The results have been interpreted in terms of ion-ion, ion-polar, hydrophilic-hydrophilic and hydrophobichydrophobic group interactions in the mixed ternary solutions.

Keywords: Apparent molar volume, viscosity Bcoefficient, isentropic compressibility, amino acid.

\section{Introduction}

Amino acids exist as zwitterions in aqueous solution. These dipolar ions should reflect structural interactions with water molecules as in the case of electrolytes. The properties of amino acids in aqueous alcohol solutions have been studied by some workers (Mishra \& Ahluwalia, 1981; Romero et al., 1999; Banipal et al., 2001), in order to understand the solute-solute interactions and the effects of various alcohols on proteins. It has been reported (Back et al., 1979; Banipal et al., 2001) that polyhydric alcohols increase the thermal stability of proteins or reduce the extent of their denaturation by other reagents. The properties of solutions of polyols in aqueous and mixed solutions are important in many areas of applied chemistry and are essential for understanding the chemistry of biological systems (Bastos,1993; Kharakoz, 1991) and act as vehicles for pharmaceuticals or cosmetics when introduce into living organisms. Resorcinol is an important organic compound, used externally as an antiseptic and disinfectant. It is also used as a chemical intermediate for the synthesis of pharmaceuticals and some organic compounds.
An emerging use of resorcinol is as a template molecule in supramolecular chemistry. The $-\mathrm{OH}$ groups on resorcinol form hydrogen bonds to target molecules holding them in the proper orientation for a reaction. Resorcinol is readily soluble in water through hydrogen bonding.

Among the various physical parameters, the apparent molar volumes at infinite dilution have been recognized as a quantity that is sensitive to structural changes occurring in solutions. In the present work we have studied the standard partial molar volumes of transfer of a homologous series of four amino acids in three different concentrations of aqueous resorcinol solutions and interpreted the results in terms of possible interactions between solute and solvent molecules.

\section{Materials and methods}

The amino acids used were glycine (Analar,>99\%), L-alanine (S.D. fine Chemicals, $>98.5 \%$ ), L-valine (Loba Chemie, India, $>99 \%$ ), L-leucine (Loba Chemie, India, >99\%) and were purified by re-crystallizing from methanolwater mixture and dried at $373.15 \mathrm{~K}$ for $12 \mathrm{~h}$ in vacuum desiccator over $\mathrm{P}_{2} \mathrm{O}_{5}$ before use.

Resorcinol (Sd. Fine Chemical Limited) was purified by a reported procedure (Franzosini \& Edgar, 1984; Roy et al., 2005), and the compound was dried and stored in a vacuum desiccator. Freshly distilled conductivity water was used for the preparation of different aqueous resorcinol solutions. The physical properties of different aqueous resorcinol solutions are listed in Table 1.

Stock solutions of resorcinol in different aqueous resorcinol solutions were prepared by mass and the working solutions were prepared by mass dilution. The conversion of molality into molarity was accomplished using experimental density values. All solutions were prepared afresh

Table 1. Experimental densities ( $\rho)$, viscosities ( $\eta)$, sound speed $(u)$ of aqueous resorcinol solutions at all experimental concentration at $298.15 \mathrm{~K}$

\begin{tabular}{|c|c|c|c|}
\hline $\begin{array}{c}\text { Molality of } \\
\text { resorcinol in } \\
\text { water(mol } \\
\mathrm{kg}^{-1} \text { ) }\end{array}$ & $\rho \times 10^{-3} / \mathrm{kg} \cdot \mathrm{m}^{-3}$ & $\eta / \mathrm{mPa} . \mathrm{s}$ & $u / \mathrm{ms}^{-1}$ \\
\hline $\mathrm{m}_{\mathrm{s}}=0.05$ & 0.9992 & 0.9013 & 1572.3 \\
$\mathrm{~m}_{\mathrm{s}}=0.10$ & 1.0003 & 0.9102 & 1721.1 \\
$\mathrm{~m}_{\mathrm{s}}=0.15$ & 1.0012 & 0.9208 & 1908.3 \\
\hline
\end{tabular}


Table 2. Experimental molalities $\mathrm{m} / \mathrm{mol}^{-1} \mathrm{~kg}^{-7}$, densities $\rho \times 10^{3} / \mathrm{kg}^{\prime} \mathrm{m}^{-3}$, viscosities $\eta / m \cdot P a \cdot s$, sound speed $u / m s^{-1}$, apparent lume of the solute $V_{\phi}$ $\times 10^{6} / \mathrm{m}^{3} \cdot \mathrm{mol}^{1}$ and partial molal isentropic compressibility $\mathrm{K} \phi \times 10^{10} / \mathrm{m}^{3} \cdot \mathrm{mol}$ ${ }^{1} \mathrm{~Pa}^{-1}$ along with the concentration $m_{s}$ of Glycine, DL-Alanine, L-Valine and LLeucine in aqueous resorcinol solutions as a function of the molalities of Amino Acids. ${ }^{a}$

\begin{tabular}{|c|c|c|c|c|c|}
\hline \\
\hline $\mathrm{m} / \mathrm{mol} \cdot \mathrm{kg}^{-1}$ & $\begin{array}{l}\rho \times 10^{-} \\
3 / \mathrm{kg} \cdot \mathrm{m}^{-3}\end{array}$ & $\eta / \mathrm{m} \cdot \mathrm{Pa} \cdot \mathrm{s}$ & $u / \mathrm{ms}^{-1}$ & $\begin{array}{l}V \phi \times 10^{6} / \\
\mathrm{m}^{3} \cdot \mathrm{mol}^{-1}\end{array}$ & $\begin{array}{c}K \phi \times 10^{10} / \\
\mathrm{m}^{3} \cdot \mathrm{mol}^{-1} \cdot \mathrm{Pa}^{-1}\end{array}$ \\
\hline \multicolumn{6}{|c|}{$\mathrm{m}_{\mathrm{s}}=.05$} \\
\hline \multicolumn{6}{|c|}{ Glycine } \\
\hline 0.0246 & 1.0000 & 0.9066 & 1710.7 & 43.53 & -25.78 \\
\hline 0.0322 & 1.0002 & 0.9082 & 1757.7 & 43.84 & -25.34 \\
\hline 0.0566 & 1.0010 & 0.9123 & 1933.4 & 43.78 & -24.41 \\
\hline 0.0726 & 1.0014 & 0.9143 & 2077.0 & 44.01 & -23.97 \\
\hline 0.0888 & 1.0020 & 0.9169 & 2268.1 & 43.95 & -23.82 \\
\hline 0.101 & 1.0023 & 0.9191 & 2451.8 & 43.99 & -23.72 \\
\hline \multicolumn{6}{|c|}{ L-Alanine } \\
\hline 0.0258 & 0.9999 & 0.9088 & 1704.8 & 60.29 & -23.66 \\
\hline 0.0358 & 1.0002 & 0.9118 & 1761.6 & 60.33 & -23.20 \\
\hline 0.0632 & 1.0010 & 0.9185 & 1947.5 & 60.36 & -22.47 \\
\hline 0.0793 & 1.0015 & 0.9220 & 2081.5 & 60.36 & -22.07 \\
\hline 0.0978 & 1.0020 & 0.9262 & 2280.7 & 60.38 & -21.85 \\
\hline 0.1114 & 1.0024 & 0.9296 & 2455.5 & 60.44 & -21.55 \\
\hline \multicolumn{6}{|c|}{ L-Valine } \\
\hline 0.0263 & 0.9999 & 0.9087 & 1741.2 & 90.43 & -28.63 \\
\hline 0.0337 & 1.0001 & 0.9119 & 1793.5 & 90.45 & -28.01 \\
\hline 0.0596 & 1.0008 & 0.9208 & 2029.5 & 90.50 & -27.32 \\
\hline 0.0762 & 1.0012 & 0.9271 & 2225.1 & 90.46 & -26.74 \\
\hline 0.0951 & 1.0018 & 0.9346 & 2527.6 & 90.48 & -26.21 \\
\hline 0.1101 & 1.0021 & 0.9405 & 2862.8 & 90.52 & -25.77 \\
\hline \multicolumn{6}{|c|}{ L-Leucine } \\
\hline 0.0252 & 0.9998 & 0.9097 & 1762.3 & 106.12 & -32.99 \\
\hline 0.0360 & 1.0001 & 0.9143 & 1856.9 & 106.20 & -32.01 \\
\hline 0.0619 & 1.0007 & 0.9226 & 2174.1 & 106.18 & -31.34 \\
\hline 0.0753 & 1.0011 & 0.9282 & 2398.0 & 106.21 & -30.78 \\
\hline 0.0954 & 1.0016 & 0.9394 & 2923.5 & 106.27 & -30.26 \\
\hline 0.1091 & 1.0019 & 0.9507 & 3565.7 & 106.24 & -29.97 \\
\hline \multicolumn{6}{|c|}{$\mathrm{m}_{\mathrm{s}}=0.10$} \\
\hline \multicolumn{6}{|c|}{ Glycine } \\
\hline 0.0243 & 1.0011 & 0.9149 & 1858.2 & 43.78 & -19.91 \\
\hline 0.0325 & 1.0013 & 0.9163 & 1902.7 & 43.81 & -19.04 \\
\hline 0.0573 & 1.0021 & 0.9201 & 2074.9 & 44.02 & -18.51 \\
\hline 0.0731 & 1.0026 & 0.9228 & 2179.0 & 43.90 & -17.49 \\
\hline 0.0897 & 1.0031 & 0.9247 & 2274.2 & 43.84 & -16.19 \\
\hline 0.1018 & 1.0034 & 0.9271 & 2366.4 & 44.09 & -15.72 \\
\hline
\end{tabular}

before use. The uncertainty in molarity of the resorcinol solutions is evaluated to $\pm 0.0001 \mathrm{~mol}$ $\mathrm{dm}^{-3}$. http://www.indjst.org Vol.2 No 1 (Jan. 2009)
Densities $\quad(\rho)$ were measured with an OstwaldSprengel type pycnometer having a bulb volume of about $25 \mathrm{~cm}^{3}$ and an internal diameter of the capillary of about $0.1 \quad \mathrm{~cm}$. The measurements were done in a thermo stated bath controlled to $\pm 0.01 \mathrm{~K}$. The viscosity was measured by means of a suspended Ubbelohde type viscometer, calibrated at $298.15 \mathrm{~K}$ with triply distilled water and purified methanol using density and viscosity values from the literature. The flow times were accurate to $\pm 0.1 \mathrm{~s}$, and the uncertainty in the viscosity measurements, based on our work on several pure liquids, was $\pm 2 \times 10^{-4}$ $\mathrm{mPa} \mathrm{s}$. The mixtures were prepared by mixing known volume of pure liquids in airtight-stopper bottles and each solution thus prepared was distributed into three recipients to perform all the measurements in triplicate, with the aim of determining possible dispersion of the results obtained. Adequate precautions were taken to minimize evaporation losses during the actual measurements. The reproducibility in mole fraction was within \pm 0.0002 units. The mass measurements were done on a Mettler AG-285 electronic balance with a precision of $\pm 0.01 \mathrm{mg}$. The precision of density measurements was $\pm 3 \times 10$-4 $\mathrm{g} \mathrm{cm}^{-3}$.

Ultrasonic speeds of sound $(u)$ were determined by a multifrequency ultrasonic interferometer (Mittal enterprise, New Delhi, M-81) working at $2 \mathrm{MHz}$, calibrated with triply distilled and purified water, methanol and benzene at $298.15 \mathrm{~K}$. The precision of ultrasonic speed measurements was $\pm 0.2 \mathrm{~m} \mathrm{~s}^{-1}$. The details of the 


\begin{tabular}{|c|c|c|c|c|c|}
\hline \multicolumn{6}{|c|}{ Table 2 continues...... } \\
\hline \multicolumn{6}{|c|}{ L-Alanine } \\
\hline 0.0253 & 1.0010 & 0.9173 & 1873.2 & 60.27 & -20.94 \\
\hline 0.035 & 1.0013 & 0.9196 & 1935.4 & 60.56 & -20.32 \\
\hline 0.0617 & 1.0021 & 0.9261 & 2149.6 & 60.55 & -19.75 \\
\hline 0.0768 & 1.0025 & 0.9299 & 2298.5 & 60.67 & -19.41 \\
\hline $\begin{array}{l}0.0969 \\
0.1104\end{array}$ & $\begin{array}{l}1.0031 \\
1.0034\end{array}$ & $\begin{array}{l}0.9348 \\
0.9371\end{array}$ & $\begin{array}{l}2541.6 \\
27391\end{array}$ & $\begin{array}{l}60.74 \\
60.97\end{array}$ & $\begin{array}{l}-18.94 \\
-18.57\end{array}$ \\
\hline \multicolumn{6}{|c|}{ L-Valine } \\
\hline 0.0258 & 1.0010 & 0.9163 & 1933.8 & 89.42 & -27.34 \\
\hline 0.0344 & 1.0013 & 0.9195 & 2007.9 & 89.55 & -26.16 \\
\hline 0.0621 & 1.0020 & 0.9269 & 2336.3 & 89.46 & -24.95 \\
\hline 0.0784 & 1.0025 & 0.9343 & 2575.3 & 89.34 & -23.90 \\
\hline 0.0964 & 1.0030 & 0.9420 & 3007.3 & 89.18 & -23.60 \\
\hline 0.1102 & 1.0034 & 0.9468 & 3428.6 & 89.12 & -22.95 \\
\hline \multicolumn{6}{|c|}{ L-Leucine } \\
\hline 0.0248 & 1.0009 & 0.9067 & 1954.9 & 106.30 & -30.74 \\
\hline 0.0349 & 1.0012 & 0.9115 & 2073.4 & 106.36 & -30.19 \\
\hline 0.0613 & 1.0018 & 0.9220 & 2536.5 & 106.35 & -29.79 \\
\hline 0.0760 & 1.0022 & 0.9276 & 2934.8 & 106.39 & -29.20 \\
\hline 0.0941 & 1.0026 & 0.9370 & 3826.2 & 106.38 & -28.65 \\
\hline 0.1068 & 1.0029 & 0.9440 & 4649.0 & 106.40 & -27.30 \\
\hline \multicolumn{6}{|c|}{$m_{s}=0.15$} \\
\hline \multicolumn{6}{|c|}{ Glycine } \\
\hline 0.0243 & 1.0020 & 0.9247 & 2027.1 & 43.84 & -12.98 \\
\hline 0.0326 & 1.0022 & 0.9260 & 2073.2 & 43.80 & -12.98 \\
\hline 0.0573 & 1.0030 & 0.9294 & 2176.9 & 43.87 & -11.20 \\
\hline 0.0732 & 1.0035 & 0.9323 & 2230.3 & 43.83 & -10.15 \\
\hline 0.09 & 1.0040 & 0.9348 & 2266.5 & 43.93 & -8.98 \\
\hline 0.1024 & 1.0044 & 0.9367 & 2252.3 & 43.90 & -7.67 \\
\hline \multicolumn{6}{|c|}{ L-Alanine } \\
\hline 0.0258 & 1.0019 & 0.9267 & 2059.8 & 60.63 & -15.18 \\
\hline 0.0346 & 1.0022 & 0.9294 & 2116.2 & 60.69 & -14.92 \\
\hline 0.0619 & 1.0029 & 0.9356 & 2310.8 & 60.82 & -14.18 \\
\hline 0.0792 & 1.0034 & 0.9385 & 2450.0 & 60.76 & -13.70 \\
\hline 0.0972 & 1.0039 & 0.9431 & 2603.0 & 60.86 & -13.12 \\
\hline 0.1098 & 1.0043 & 0.9469 & 2723.7 & 60.91 & -12.78 \\
\hline \multicolumn{6}{|c|}{ L-Valine } \\
\hline 0.0257 & 1.0019 & 0.9260 & 2169.2 & 89.08 & -24.22 \\
\hline 0.0353 & 1.0022 & 0.9279 & 2291.4 & 89.03 & -23.89 \\
\hline 0.0627 & 1.0030 & 0.9370 & 2674.1 & 88.98 & -21.52 \\
\hline 0.0791 & 1.0034 & 0.9430 & 3040.2 & 89.01 & -21.05 \\
\hline 0.0968 & 1.0039 & 0.9495 & 3669.7 & 88.99 & -20.69 \\
\hline 0.1108 & 1.0043 & 0.9556 & 4098.9 & 88.95 & -19.4 \\
\hline \multicolumn{6}{|c|}{ L-Leucine } \\
\hline 0.0246 & 1.0018 & 0.9038 & 2195.7 & 106.53 & -27.36 \\
\hline 0.0352 & 1.0021 & 0.9101 & 2336.7 & 106.55 & -26.02 \\
\hline 0.0627 & 1.0027 & 0.9196 & 2878.6 & 106.58 & -24.56 \\
\hline 0.0792 & 1.0031 & 0.9274 & 3321.8 & 106.55 & -23.23 \\
\hline 0.0975 & 1.0036 & 0.9365 & 4208.9 & 106.61 & -22.36 \\
\hline 0.1107 & 1.0039 & 0.9436 & 5232.3 & 106.58 & -21.78 \\
\hline
\end{tabular}

methods and techniques had been described elsewhere (Roy et al., 2005, 2006).

\section{Results}

Apparent molar volumes at infinite dilution and compressibility

Densities of aqueous solutions of amino acids containing resorcinol determined at 298.15K are given in Table 2. These data were used to calculate the apparent molar volumes of the solute $V_{\phi}$ using the following equation (Munde \& Kishore, 2003; Roy et al., 2006),

$V_{\phi}=M / \rho-1000\left(\rho-\rho_{0}\right) / m \rho \rho_{0}$

where $M$ is the molar mass of the solute in $\mathrm{g} \cdot \mathrm{mol}^{-1}, m$ is the molality of solute in $\mathrm{mol} \cdot \mathrm{kg}^{-1}$ in the resorcinol-water mixture, and $\rho$ and $\rho_{\mathrm{o}}$ are the densities of the solution and the solvent, respectively. The apparent molar volumes of the amino acids were found to be a linear function of molality over the studied concentration range. Hence, values of the apparent molar volumes or partial molar volume at infinite dilution, $V_{\phi}^{0}$, were calculated by least-squares fitting using the following Masson equation (Masson, 1929; Pandey et al., 1987):

$V_{\phi}=V_{\phi}^{0}+S_{V}^{*} V_{m}$

$V_{\phi}^{0} \quad$ provides information regarding solutesolvent interactions; $S_{v}{ }^{*}$ is the experimental slope, which is sometimes called volumetric pair wise interactions coefficient (Hedwig et al., 1991) and is a measure of solute-solute interactions and $m$ is the molality of the solute (amino acid). The regression coefficients $V_{\phi}^{0}$ and $S_{V}$ of Eq. (2) for the amino acids in aqueous resorcinol are presented in Table 3. where values of $V_{\phi}^{0}$ and $S_{v}{ }^{*}$ for the amino acids in pure water are adapted from the literature (Millero et al., 1978; Li et al., 2006).

The isentropic compressibility, $K_{S}$, of the solution was calculated from the Laplace's equation:

$K_{S}=1 /\left(u^{2} \rho\right)$

where $\rho$ is the solution density and $u$ is the ultrasonic speed in the solution.

The apparent molal isentropic compressibility, $K_{\phi}$, of the solutions was determined from the relation:

$K_{\phi}=K_{S} M / \rho+1000\left(K_{S} \rho_{0}-K_{S}^{0} \rho\right) / m \rho \rho_{0}$

$K_{S}^{0}$ is the isentropic compressibility of the solvent mixture, $M$ is the molar mass of the solute, and $m$ is the molality of the solution.

The limiting apparent molal isentropic compressibility, $K_{\phi}^{0}$,was obtained by extrapolating the plots of $K_{\phi}$ versus the square root of molal concentration of the solute, $\sqrt{ } m$ to zero concentration by a least-squares method (Wadi \& Ramasmi,1997),

$K_{\phi}=K_{\phi}^{0}+S_{K}^{*} \sqrt{ } m$ 
where, $S_{K}{ }^{*}$ is the experimental slope. The regression coefficients $K_{\phi}^{0}$ and $S_{K}^{*}$ of Eq. (5) for the Table 4.

$V_{\phi}^{0}$ and $K_{\phi}^{0}$ values are by definition free from solute- solute interactions and thus provide information regarding solute- solvent interactions. amino acids in aqueous resorcinol are presented in

been reported earlier by a number of workers (Millero et al., 1978; Li et al., 2006) and this linear variation can be represented as follows:

$V_{\phi}^{0}=V_{\phi}^{0}\left(\mathrm{NH}_{3}{ }^{+}, \mathrm{COO}^{-}\right)+N_{C}\left(\mathrm{CH}_{2}\right)$

where $N_{C}$ is the number of carbon atoms in the alkyl chain of the amino acids and $V_{\phi}^{0}\left(\mathrm{NH}_{3}{ }^{+}, \mathrm{COO}\right)$ and $V_{\phi}^{0}\left(\mathrm{CH}_{2}\right)$ are the zwitterionic end group and methylene contribution group respectively. The values of $V_{\phi}^{0}\left(\mathrm{NH}_{3}{ }^{+}, \mathrm{COO}\right)$ and $V_{\phi}^{0}$ $\left(\mathrm{CH}_{2}\right)$, calculated by a leastsquare regression analysis, are listed in Table 5, where those values in pure water are also provided from the literature (Banerjee \& Kishore, 2005). It is well described in the literature (Banerjee \& Kishore, 2005) that $V_{\phi}^{0}\left(\mathrm{CH}_{2}\right)$ obtained by this scheme characterizes the mean contribution of the $\mathrm{CH}$ - and $\mathrm{CH}_{3}$ - groups to $V_{\phi}^{0}$ of the amino acids. The contribution of the other alkyl chains of the amino acids has been calculated using a scheme, as suggested by Hakin et al. $(1994 a, b)$

$V_{\phi}^{0}\left(\mathrm{CH}_{3}\right)=1.5 V_{\phi}^{0}\left(\mathrm{CH}_{2}\right)(7)$ $V_{\phi}^{0}(\mathrm{CH})=0.5 V_{\phi}^{0}\left(\mathrm{CH}_{2}\right)(8)$ and are listed in Table 5 . It shows that the contribution of $\left(\mathrm{NH}_{3}{ }^{+}, \mathrm{COO}\right)$ to $V_{\phi}^{0}$ is larger than that of the $\mathrm{CH}_{2}$ group and increases with the increase in the concentration of the cosolute, which indicates that the interactions between the co-solute and charged end groups $\left(\mathrm{NH}_{3}{ }^{+}, \mathrm{COO}^{-}\right)$of amino acids are much stronger that those between the co-solute and $\mathrm{CH}_{2}$.

The standard partial molar volumes of transfer of

Solute- solute interactions can be understood from the $S_{V}{ }^{*}$ and $S_{K}{ }^{*}$ values.

Contributions of the zwitterionic end group, $\mathrm{CH}_{2}$ groups and other alkyl chains of the $\alpha$-amino acids to $V_{\phi}^{0}$

At each molality, the $V_{\phi}^{0}$ value varies linearly with the number of carbon atoms in the alkyl chain $(R)$ of the amino acids. Similar correlations have the zwitterionic end group, $V_{\phi}^{0}\left(\mathrm{NH}_{3}{ }^{+}, \mathrm{COO}\right)$, and other alkyl chain groups, $V_{\phi}^{0}(\mathrm{R})$, of amino acids from water to co-solute solutions have been calculated as follows,

$\Delta_{t r} V_{\phi}^{0}\left(\mathrm{NH}_{3}{ }^{+}, \mathrm{COO}^{-}\right)$or $\Delta_{t r} V_{\phi}^{0}(\mathrm{R})=$

$$
V_{\varnothing}^{O}\left(\mathrm{NH}_{3}{ }^{+}, \mathrm{COO}^{-}\right) \text {or } V_{\varnothing}{ }^{0}(\mathrm{R})
$$


Table 5. Contribution of the Zwitterionic End Group $\left(\mathrm{NH}_{3}{ }^{+} \mathrm{COO}^{-}\right), \mathrm{CH}_{2}$ - Group, and Other Alkyl Chain Groups $(R)$ to Standard Partial Molar Volume, $V_{\phi}^{0}$, and Transfer Volumes, $\Delta_{t r} V_{\phi}^{0}$ in Different Aqueous Resorcinol Solutions at $298.15 \mathrm{~K}$

\begin{tabular}{|c|c|c|c|c|c|c|c|}
\hline \multirow{2}{*}{ group } & \multicolumn{4}{|c|}{$V_{\phi}^{0} \times 10^{6} / \mathrm{m}^{3} \cdot \mathrm{mol}^{-1}$} & \multicolumn{3}{|c|}{$\Delta_{t r} V_{\phi}^{0} \times 10^{6} / \mathrm{m}^{3} \cdot \mathrm{mol}^{-1}$} \\
\hline & water & $\mathrm{m}_{\mathrm{s}}=0.05$ & $\mathrm{~m}_{\mathrm{s}}=0.10$ & $\mathrm{~m}_{\mathrm{s}}=0.15$ & $\mathrm{~m}_{\mathrm{s}}=0.05$ & $\mathrm{~m}_{\mathrm{s}}=0.10$ & $\mathrm{~m}_{\mathrm{s}}=0.15$ \\
\hline $\mathrm{NH}_{3}^{+} \mathrm{COO}^{-}$ & 27.68 & 28.25 & 28.49 & 28.76 & 0.57 & 0.81 & 1.08 \\
\hline $\mathrm{CH}_{2-}$ & 15.91 & 15.57 & 15.50 & 15.41 & -0.34 & -0.41 & -0.50 \\
\hline $\mathrm{CH}_{3} \mathrm{CH}-$ & 31.82 & 31.14 & 31.00 & 30.82 & -0.68 & -0.82 & -1.00 \\
\hline$\left(\mathrm{CH}_{3}\right)_{2} \mathrm{CHCH}-$ & 63.64 & 62.28 & 61.99 & 61.63 & -1.36 & -1.65 & -2.01 \\
\hline$\left(\mathrm{CH}_{3}\right)_{2} \mathrm{CHCH}_{2} \mathrm{CH}-$ & 79.45 & 77.86 & 77.49 & 77.04 & -1.60 & -1.96 & -2.41 \\
\hline
\end{tabular}

[in aqueous cosolute] -

$V_{\varnothing}{ }^{0}\left(\mathrm{NH}_{3}{ }^{+}, \mathrm{COO}^{-}\right)$or $V_{\varnothing}{ }^{0}(\mathrm{R})$ [in water]

(9)

and are included in Table 5 and illustrated in Fig. 2.

The contribution of $\left(\mathrm{NH}_{3}{ }^{+}, \mathrm{COO}\right)$ to $\Delta_{t r} V_{\phi}^{0}$ is positive throughout the studied concentration range of the co-solute and increases with the increase in the concentration of the co-solute. The contribution of the alkyl chain groups to $\Delta_{t r} V_{\phi}^{0}$ is negative for all the amino acids, and their contribution decreases with the increase in the number of carbon atoms.

The side chain contribution to the partial molar volume of the amino acids can be derived from the difference between the $V_{\varnothing}{ }^{0}$ values of each amino acid and that of glycine using the following scheme:

$V_{\phi}^{0}(\mathrm{R})=V_{\phi}^{0}$ (amino acid) - $V_{\phi}^{0}$ (glycine)

where $V_{\phi}^{0}(\mathrm{R})$ defines the side chain contribution to $V_{\phi}^{0}$ of the respective amino acid relative to the $\mathrm{H}$ atom of glycine. In this scheme, it is assumed that the volume contribution of the $\mathrm{H}$-atom in glycine is negligible. The results are listed in Table 6.

The number of water molecules hydrated to the amino acids $\left(N_{w}\right)$ in aqueous resorcinol solutions

The number of water molecules hydrated to the amino acids, $N_{w}$ was calculated from the value of measured standard partial molar volume by the following manner.

The values of $V_{\phi}^{0}$ of the studied amino acids can be expressed as (Millero et al., 1978; Franks et al., 1970),

$V_{\phi}^{0}=V_{\phi}^{0}$ (int) $+V_{\phi}^{0}$ (elect)

where $V_{\phi}^{0}$ (int) is the intrinsic partial molar volume of the amino acid and $V_{\varnothing}^{0}$ (elect) is the electrostriction partial molar volume as a result of hydration of the amino acids the $V_{\varnothing}^{0}$ (int) consists of two terms: the van der Waals volume and the volume due to packing effects. The values of $V_{\phi}^{0}$ (int) for the amino acids were calculated from their crystal molar volume by Millero et al (1978) using the following relationship,

$V_{\phi}^{0}$ (int) $=(0.7 / 0.634) V_{\phi}^{0}$ (cryst)

where, 0.7 is the packing density in an organic crystal and 0.634 is the packing density of randomly packed spheres. The molar volume of crystals was calculated using the crystal densities of the amino acids represented by Berlin and Pallansch (1968) at $298.15 \mathrm{~K}$. The values of $V_{\phi}^{0}$ (elect) were obtained from the experimentally determined $V_{\phi}^{0}$ values using Eq.11.

The number of water molecules hydrated to the amino acids due to electrostriction causes decrease in volume can be related to the hydration numbers (Millero et al., 1978),

$N w=$ $\checkmark \phi 0$ (elect)

$V E O-V B O$

where $V_{E}^{0}$ is the molar volume of electrostricted water and $V_{B}^{0}$ is the molar volume of bulk water. This model implies that for every water molecules taken from the bulk phase to the surroundings of amino acid, the volume is decreased by $\left(V_{E}^{0}-V_{B}^{0}\right)$, using a value of $-3.0 \mathrm{~cm}^{3} \cdot \mathrm{mol}^{-1}$ (Millero et al., 1978). The obtained $N_{w}$ values are listed in Table 7.

Fig. 1. The transfer volumes of Glycine( $\bullet), D L-$ Alanine (๘), L-Valine ( $\triangle$ ), L-Leucine ( $x$ ), from water to aqueous resorcinol solutions plotted against the molarity $m_{s}$ of the resorcinol solutions at $298.15 \mathrm{~K}$.

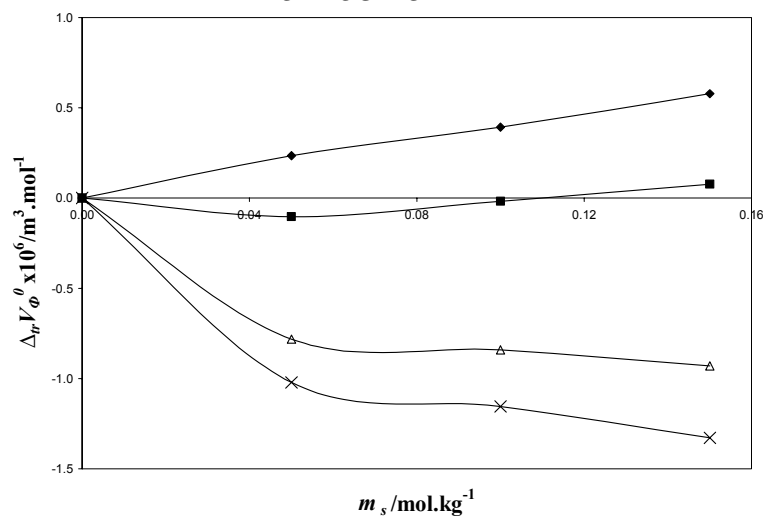

Partial molar volume of transfer from water to aqueous resorcinol solution

The values of partial molar volume of transfer and partial molar compressibility of transfer of the 
amino acid (Li et al., 2006) from pure water to resorcinol are obtained from the eqns.

$\Delta_{t r} V_{\phi}^{0}$ (water to aqueous resorcinol) $=V_{\phi}^{0}$

(in aqueous resorcinol) - $V_{\phi}^{0}$ (in water)

$\Delta_{t r} K_{\phi}^{0}$ (water to aqueous resorcinol) $=K_{\phi}^{0}$

(in aqueous resorcinol) - $K_{\phi}^{0}$ (in water)

Table 6. Contribution of the alkyl chain group $(R)$ to standard partial molar volume, $V_{\phi}^{0}(R)$, and viscosity $B$-coefficient $B(R)$ in different aqueous resorcinol solutions at $298.15 \mathrm{~K}$

\begin{tabular}{|c|c|c|c|c|c|c|}
\hline \multirow{2}{*}{ Group } & \multicolumn{3}{|c|}{$V_{\phi}^{0}(\mathrm{R}) \times 10^{6} / \mathrm{m}^{3} \cdot \mathrm{mol}^{-1}$} & \multicolumn{3}{c|}{$B(\mathrm{R}) / \mathrm{m}^{3} \cdot \mathrm{mol}^{-1}$} \\
\cline { 2 - 7 } & $\mathrm{m}_{\mathrm{s}}=0.05$ & $\mathrm{~m}_{\mathrm{s}}=0.10$ & $\mathrm{~m}_{\mathrm{s}}=0.15$ & $\mathrm{~m}_{\mathrm{s}}=0.05$ & $\mathrm{~m}_{\mathrm{s}}=0.10$ & $\mathrm{~m}_{\mathrm{s}}=0.15$ \\
\hline L-alanine & 16.90 & 16.62 & 16.87 & 0.094 & 0.09 & 0.08 \\
L-valine & 47.09 & 46.28 & 45.43 & 0.312 & 0.31 & 0.30 \\
L-leucine & 62.76 & 62.66 & 62.76 & 0.430 & 0.46 & 0.50 \\
\hline
\end{tabular}

Table 7. Hydration number $\left(N_{w}\right)$ of amino acids in aqueous resorcinol at $298.15 \mathrm{~K}$.

\begin{tabular}{|c|c|c|c|}
\hline \multirow{2}{*}{ Amino acids } & \multicolumn{3}{|c|}{$N_{w}$} \\
\cline { 2 - 4 } & $\mathrm{m}_{\mathrm{s}}=0.05$ & $\mathrm{~m}_{\mathrm{s}}=0.10$ & $\mathrm{~m}_{\mathrm{s}}=0.15$ \\
\hline glycine & 2.9 & 2.8 & 2.7 \\
L-alanine & 3.9 & 3.8 & 3.7 \\
L-valine & 4.0 & 4.2 & 4.4 \\
L-leucine & 6.0 & 6.0 & 6.0 \\
\hline
\end{tabular}

Table 8. Transfer volumes of amino acids $\left(\Delta_{t r} V_{\phi}^{0}\right.$ $\left.\times 10^{6} / \mathrm{m}^{3} \cdot \mathrm{mol}^{1}\right)$ and Transfer compressibilities of amino acids $\left(\Delta_{t r} K_{\phi}^{0} \times 10^{6} / \mathrm{m}^{3} \cdot \mathrm{mol}^{1}\right)$ from water to aqueous resorcinol, at $298.15 \mathrm{~K}$.

\begin{tabular}{|c|c|c|c|}
\hline & \multicolumn{3}{|c|}{$\Delta_{t r} V_{\phi}^{0} \times 10^{6} / \mathrm{m}^{3} \cdot \mathrm{mol}^{-1}$} \\
\hline $\begin{array}{r}\text { Amino- } \\
\text { acids }\end{array}$ & $\mathrm{m}_{\mathrm{s}}=0.05$ & $\mathrm{~m}_{\mathrm{s}}=0.1$ & $\mathrm{~m}_{\mathrm{s}}=0.15$ \\
\hline glycine & 0.24 & 0.39 & 0.58 \\
L-alanine & -0.10 & -0.02 & 0.08 \\
L-valine & -0.78 & -0.84 & -0.93 \\
L-leucine & -1.02 & -1.15 & -1.33 \\
\hline & \multicolumn{3}{|c|}{$\Delta_{t r} K_{\phi}^{0} \times 10^{6} / \mathrm{m}^{3} \cdot \mathrm{mol}^{-1}$} \\
\hline glycine & -0.70 & 3.20 & 8.48 \\
L-alanine & -1.06 & 2.39 & 7.74 \\
L-valine & -0.50 & -0.33 & 1.91 \\
L-leucine & -3.67 & -1.83 & -0.33 \\
\hline These
\end{tabular}

These results are reported in Table 8, graphically shown in Fig 1. \& Fig 3. respectively. Viscosity B-Coefficient.

The experimental viscosity data for the systems studied are listed in Table 2 . The relative viscosity $\left(\eta_{r}\right)$ has been analyzed using the Jones-Dole equation (Jones \& Dole, 1929; Anwar et al., 2007), $\eta_{r}=\eta / \eta_{0}=1+A \sqrt{ } c+B c$

where $\eta$ and $\eta_{0}$ are the viscosities of the ternary solutions (amino acid + resorcinol + water) and binary solvents (resorcinol + water)and $c$ is the molarity of the amino acids in ternary solutions. $A$ and $B$ are empirical constants known as viscosity
$A$ - and $B$-coefficients, which are specific to solutesolute and solute solvent interactions, respectively. Eq. 15 can be rearranged as,

$\left(\eta_{r}-1\right) / \sqrt{ } c=A+B \sqrt{ } c$

Values of $A$ - and $B$-coefficients are obtained from a linear plot of the left-hand side of Eq. 16 vs $\sqrt{ } c$. The values of $A$ - and $B$ coefficients are listed in Table 9. Due to the complex nature of $A$ coefficients, they are not discussed in the present work. Table 9 shows that $B$ coefficients are positive for all the amino acids and increase with the increase of the size of the side chains. The $B$ coefficients reflect the net structural effects of the charged groups and the hydrophobic $\mathrm{CH}_{2-}$ groups on the amino acids. As $B$-coefficients vary linearly with the number of carbon atoms of the alkyl chain $\left(N_{C}\right)$, these two effects can be resolved as follows

$B=B\left(\mathrm{NH}_{3}^{+}, \mathrm{COO}^{-}\right)+N_{\mathrm{C}} B\left(\mathrm{CH}_{2}\right)$

The regression parameters, i.e., the zwitterionic group contribution, $\left.B\left(\mathrm{NH}_{3}{ }^{+}, \mathrm{COO}^{-}\right)\right)$, and the methylene group contribution, $B\left(\mathrm{CH}_{2}\right)$, to $B$ coefficients are listed in Table 10. It shows that $B\left(\mathrm{NH}_{3}{ }^{+}, \mathrm{COO}^{-}\right)$values decrease while $B\left(\mathrm{CH}_{2}\right)$ values increase with increasing concentration of resorcinol in ternary solutions, indicating that the zwitterionic groups break while the $\mathrm{CH}_{2}$-group enhances the structure of the aqueous salt solutions. The side chain contributions to $B$-coefficients, $B(\mathrm{R})$, have also been derived using the same scheme as that of $V_{\phi}^{0}(\mathrm{R})$ and are listed in Table 5, which shows that $B(\mathrm{R})$ values are positive and follow the order: L-leucine $>$ Lvaline $>\mathrm{L}$-alanine. This order is due to the greater structure breaking tendency of Lleucine as compared to L-valine and Lalanine, and these findings are in line with our volumetric results discussed earlier.

The viscosity data are also analyzed on the basis of transition state theory for relative viscosity of the acetate solutions as suggested by Feakins et al. (1974) using Eq 18:

$\Delta \mu_{2}{ }^{*}=\Delta \mu_{1}{ }^{*}+\left(R T / V_{1}\right)\left(1000 B+V_{2}-V_{1}\right)$ where $\Delta \mu_{2}{ }^{*}$ is the contribution per mole of the solute to free energy of activation for viscous flow of solutions and $\Delta \mu_{1}{ }^{*}$ is the free energy of activation per mole of solvent mixture. The values are reported in Table $10 . \nu_{1}$ is the apparent (partial) molar volume of the solvent (aqueousresorcinol) and $V_{2}$ is the limiting apparent (partial) molar volume of the solute, respectively. $\Delta \mu_{1}{ }^{*}$ is calculated from 
Table 9. Values of $A$ - and $B$-coefficients for the amino acids and the contributions of $\left(\mathrm{NH}_{3}{ }^{+}, \mathrm{COO}\right)$ and $\mathrm{CH}_{2}$ groups to viscosity $B$-coefficients of the amino acids in aqueous resorcinol solutions at $298.15 \mathrm{~K}$.

\begin{tabular}{|c|c|c|c|c|c|c|}
\hline & \multicolumn{3}{|c|}{$\mathrm{B} / \mathrm{m}^{3} \cdot \mathrm{mol}^{-1}$} & \multicolumn{3}{c|}{$\mathrm{A} / \mathrm{m}^{3 / 2} \cdot \mathrm{mol}^{-1 / 2}$} \\
\hline $\begin{array}{c}\text { Amino- } \\
\text { acids }\end{array}$ & $\mathrm{m}_{\mathrm{s}}=0.05$ & $\mathrm{~m}_{\mathrm{s}}=0.1$ & $\mathrm{~m}_{\mathrm{s}}=0.15$ & $\mathrm{~m}_{\mathrm{s}}=0.05$ & $\mathrm{~m}_{\mathrm{s}}=0.1$ & $\mathrm{~m}_{\mathrm{s}}=0.15$ \\
\hline glycine & 0.140 & 0.148 & 0.165 & 0.020 & 0.013 & 0.003 \\
\hline L-alanine & 0.234 & 0.241 & 0.247 & 0.016 & 0.011 & 0.002 \\
\hline L-valine & 0.453 & 0.456 & 0.463 & -0.020 & -0.031 & -0.045 \\
\hline L-leucine & 0.571 & 0.604 & 0.660 & -0.037 & -0.047 & -0.052 \\
\hline Group & \multicolumn{3}{|c|}{$\mathrm{B} / \mathrm{m}^{3} \cdot \mathrm{mol}^{-1}$} \\
\cline { 1 - 4 }$\left(\mathrm{NH}_{3}{ }^{+}, \mathrm{COO}^{-}\right)$ & 0.026 & 0.024 & 0.022 & & & \\
\cline { 1 - 3 }$\left(\mathrm{CH}_{2}\right)$ & 0.108 & 0.113 & 0.121 & &
\end{tabular}

dominance of the interaction of the charged functional groups of the zwitterionic amino acids over the pair wise interaction. With the introduction of additional methyl groups in the side chains of the amino acids, the $S_{V}{ }^{*}$ and $S_{K}{ }^{*}$ values also change, indicating that the methyl groups modulate the

$\Delta \mu^{0}{ }_{1}^{*}=\Delta G^{o}{ }_{1}^{*}=R T \ln \left(\eta_{0} V_{1} / h N_{A}\right)$

interaction of the charged end groups in pair wise interaction.

The values of $V_{\phi}^{0}$ are positive for all the amino acids in aqueous resorcinol at all molalities studied. The $V_{\phi}^{0}$ value increases gradually with the increase in concentration of aqueous resorcinol over the studied concentration range, except for the case of L-valine where $V_{\phi}^{0}$ value decreases with the increase in the molality of resorcinol.

From Table 4, it is observed that the value of limiting apparent molal isentropic compressibility $K_{\phi}^{0}$ increases with the increase in concentration of resorcinol solution for all the concentration studied but all the values are negative.

At neutral $\mathrm{pH}$, amino acid exists as zwitterions when dissolved in water and there is an overall decrease in the volume of water. This is due to the contraction of water near the end charged groups, termed as electrostriction. Hence the electrostricted water is much less compressible than bulk water and accounts for the apparent molal compressibilities for the amino acids in mixed ternary solutions being larger than the corresponding ones in water. It is also observed that the negative values of $K_{\phi}^{0}$ for the studied amino acids follow the order:

glycine $<$ L-alanine $<$ L-valine $<$ L-leucine

Since the contribution of methylene group to the apparent compressibility is negative, it implies that the ions having the larger hydrophobic group may have more negative values for the partial molal expansibilities. Hence, L-leucine may have largest hydrophobic group resulting higher negative values of $K_{\phi}^{0}$.

In Table 7, the observed decreasing tendency of $N_{w}$ for glycine and L-alanine supports the view (Ogawa et al., 1984) that the resorcinol has a dehydration effect on these amino acids in aqueous resorcinol solutions. In case of L-valine, a slight increase of $N_{w}$ indicates that the increase in the interaction of hydrophobic groups of L-valine 
with those of the salt does not reduce the electrostriction of water molecules to it, but leads to a slight increase in the hydration number, $N_{w}$. However, for L-Leucine, the $N_{w}$ values remain unaltered by resorcinol concentration. This indicates that, the hydrophobic group of L-leucine reduces the ion-ion interaction between the amino acid and the salt.

Table 10. Values of $\left(\mathrm{V}_{2}-V_{1}\right) \cdot 10^{6} /\left(\mathrm{m}^{3} \mathrm{~mol}^{1}\right)$, free energy of activation for the solvent, $\Delta \mu_{1}{ }_{1}^{*} /\left(\mathrm{kJ}^{\prime} \cdot \mathrm{mol}^{1}\right)$, and solute $\Delta \mu_{2}{ }_{2}^{*} /\left(\mathrm{kJ}^{\prime} \cdot \mathrm{mol}^{1}\right)$, for the amino acids in aqueous resorcinol at $298.15 \mathrm{~K}$.

\begin{tabular}{|c|c|c|c|c|}
\hline Parameters & Glycine & L-Alanine & $\begin{array}{c}\text { L- } \\
\text { Valine }\end{array}$ & $\begin{array}{c}\text { L- } \\
\text { Leucine }\end{array}$ \\
\hline \multicolumn{5}{|c|}{$m_{s}=0.05$} \\
\hline$\left(V_{2}-V_{1}\right) \cdot 10^{6} /\left(\mathrm{m}^{3} \cdot \mathrm{mol}^{-1}\right)$ & 25.20 & 42.09 & 72.25 & 87.91 \\
\hline$\Delta \mu_{1}^{\rho_{1}}\left(\mathrm{~kJ} \cdot \mathrm{mol}^{-1}\right)$ & 9.20 & 9.20 & 9.20 & 9.20 \\
\hline 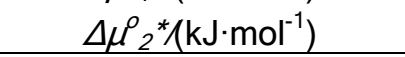 & 19.23 & 32.11 & 61.98 & 78.13 \\
\hline \multicolumn{5}{|c|}{$\mathrm{m}_{\mathrm{s}}=0.10$} \\
\hline$\left(V_{2}-V_{1}\right) \cdot 10^{6} /\left(\mathrm{m}^{3} \cdot \mathrm{mol}^{-1}\right)$ & 25.48 & 42.07 & 71.68 & 88.04 \\
\hline$\Delta \mu_{1}^{\rho_{1}}\left(\mathrm{~kJ} \cdot \mathrm{mol}^{-1}\right)$ & 9.22 & 9.23 & 9.23 & 9.24 \\
\hline$\Delta \mu_{2}{ }_{2}^{*}\left(\mathrm{~kJ} \cdot \mathrm{mol}^{-1}\right)$ & 20.29 & 32.95 & 62.22 & 82.32 \\
\hline \multicolumn{5}{|c|}{$\mathrm{m}_{\mathrm{s}}=0.15$} \\
\hline$\left(V_{2}-V_{1}\right) \cdot 10^{6} /\left(\mathrm{m}^{3} \cdot \mathrm{mol}^{-1}\right)$ & 25.57 & 42.40 & 70.89 & 88.18 \\
\hline$\Delta \mu_{1}^{\rho_{1}^{*}}\left(\mathrm{~kJ} \cdot \mathrm{mol}^{-1}\right)$ & 9.26 & 9.26 & 9.27 & 9.28 \\
\hline$\Delta \mu_{2}^{o}{ }_{2}^{*}\left(\mathrm{~kJ} \cdot \mathrm{mol}^{-1}\right)$ & 22.57 & 33.73 & 62.85 & 89.50 \\
\hline
\end{tabular}

Since the solute-solute interactions are absent at infinite dilution, the observed transfer volume reflects the solute-solvent interactions. In general, the interactions between amino acids and resorcinol can be classified into:

(i) ion-ion group interactions between the $\mathrm{NH}_{3}{ }^{+}$and $\mathrm{COO}^{-}$groups of the Zwitterionic amino acid with the $\mathrm{OH}$ groups of the resorcinol.

(ii) ion-ion polar group interactions between the $\mathrm{NH}_{3}{ }^{+}$and $\mathrm{COO}^{-}$groups of the amino acid with the phenyl group of the resorcinol.

(iii) hydrophobic-hydrophobic interactions between the hydrophobic parts of the amino acids and the hydrophobic part of the resorcinol.

According to the co-sphere overlap model of Gurney (1953), interactions of type (i) and (ii) lead to a positive $\Delta_{t r} V_{\phi}^{0}$ value, whereas type (iii) would lead to a negative $\Delta_{t r} V_{\phi}^{0}$ value because the introduction of alkyl groups provides an additional tendency for hydrophilic-hydrophobic and hydrophobic-hydrophobic group interactions leading to a reduction in the overall structure of water formed as a result of their co-sphere overlap. Positive and negative values of volume transfer were observed for the studied amino acids (Table 8). The values of $\Delta_{t r} V_{\phi}^{0}$ for glycine, L-alanine increase positively with the increasing concentration of resorcinol. However for L-valine and L-leucine, the transfer value decreases.

The observed trend can also be explained with the following equation (Natarajan et al., 1990; Bhat \& Ahluwalia, 1985):

$V_{\phi}^{0}=V_{v w}+V_{v}-V_{S}$

where $V_{\mathrm{Vw}}$ is the van der Waals volume (Bondi, 1964), occupied by solute and $V_{v}$ is the volume associated with the voids and empty spaces present therein (Bondi, 1954) and $V_{S}$ is the shrinkage volume due to electrostriction. Assuming that $V_{v w}$ and $V_{v}$ have the same magnitudes in water and in aqueous resorcinol solution for the same class of solutes (Mishra \& Ahluwalia, 1981), the observed positive $\Delta_{t r} V_{\phi}^{0}$ values for glycine can be attributed to the decrease in the volume of shrinkage. An increase in the concentration of co-solute resorcinol, results in an increase in $\Delta_{t r} V_{\phi}^{0}$ indicating an enhancement in the ion-ion interaction between the zwitterionic centres of the amino acids and the ion of the salt. A similar trend is observed in the case of L-alanine, although an additional $-\mathrm{CH}_{2}$ - group compared to glycine increases the hydrophobic interactions, leading to a reduction in the positive value of $\Delta_{t r} V_{\phi}^{0}$. The number of hydrophobic groups increases in the order, L-valine, L-leucine. The increased number of hydrophobic groups in these amino acids interacts strongly with the hydrophobic groups of resorcinol, thereby leading to negative volumes of transfer, which increases with the concentration of resorcinol. Similar observations were shown by Banerjee \& Kishore (2005).

Table 9 shows that $B$-coefficients are positive for all the amino acids and increase with the increase of the size of the side chains. The $B$ coefficients reflect the net structural effects of the charged groups and the hydrophobic $\mathrm{CH}_{2}$ - groups on the amino acids.

Table 10 reveals that $\Delta \mu_{1}{ }^{*}$ is almost constant

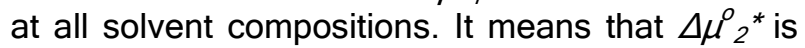
dependent mainly on the values of viscosity $B$ coefficients and $\left(V_{2}-V_{1}\right)$ terms. It is also evident that the $\Delta \mu_{2}{ }^{*}$ values are positive and much larger than the $\Delta \rho_{1}{ }^{*}$ values. This suggests that the interactions between amino acids and solvent (aqueous-resorcinol) molecules in the ground state are stronger than in the transition state. Hence in the transition state, the solvation of the solute 
molecules is less favoured in free energy. Furthermore, as $\Delta \mu_{2}^{o}{ }^{*}>\Delta \mu_{1}^{o}{ }^{*}$, for solutes having positive viscosity $B$-coefficients indicates a stronger solute-solvent interactions, thereby suggesting that the formation of transition state is accompanied by the rupture and distortion of the intermolecular forces in solvent structure (Feakins et al.,1974). The $\Delta \mu_{2}{ }^{*}$ values (Table 10) of the amino acids were found to increase from glycine to L-leucine. This indicates that the solvation of the amino acids in the transition state becomes increasingly unfavourable as the hydrophobicity (number of carbon atoms) of the side chain increases from glycine to L-leucine.

Conclusion

In summary; volume, viscosity and compressibility data have been determined for amino acids in aqueous resorcinol and the results have been used to estimate the volume and compressibility of transfer, number of hydrated water molecules and the viscosity $B$-coefficient values The study reveals that although ion-ion or hydrophilic-hydrophilic group interactions are predominant for glycine and L-alanine, ionhydrophobic or hydrophobic- hydrophobic group interactions are predominant for L-valine and Lleucine in aqueous resorcinol solutions. These interactions are a function of the molality of resorcinol in the ternary solutions. Also, it is evident that resorcinol has a dehydration effect on these amino acids in aqueous resorcinol solutions. The size and number of carbon atoms of the alkyl chain groups of the amino acids also play a pivotal role in determining the nature and strength of the interactions in these solvent media.

\section{Acknowledgement}

The authors are grateful to the Departmental Special 379 Assistance Scheme under the University Grants Commission, New Delhi (No. 540/6/DRS/2007, SAP-1) for financial support.

\section{References}

1. Anwar A, Khan S, Hyder S and Tariq M (2007) Interactions of some $\alpha$-amino acids with tetra$\mathrm{n}$ - alkylammonium bromides in aqueous medium at different temperatures. J.Chem. Thermodyn. 39, 613-620.

2. Back JF, Uakenfull D and Smith MB (1979) Increased thermal stability of proteins in the presence of sugars and polyols. Biochemistry. 19, 5191-5196.

3. Banerjee $T$ and Kishore N (2005) Interactions of some amino acids with aqueous tetraethylammonium bromide at $298.15 \mathrm{~K}$ : A volumetric approach. J. Solution Chem. 35, 137-153.

4. Banipal TS, Singh G and Lark B (2001) Partial molar volumes of transfer of some amino http://www.indjst.org Vol.2 No 1 (Jan. 2009)

acids from water to aqueous glycerol solutions at $25^{\circ} \mathrm{C}$. J.Soln. Chem. 30, 675-670.

5. Bastos M, Volkova NN and Wadso I (1993) Heat capacities of D-mannitol and D-sorbitol in water, dimethyl sulfoxide and formamide. J.Chem.Soc. Faraday Trans. 89, 1351-1352.

6. Berlin E and Pallansch MJ (1968) Densities of several proteins and L-amino acids in the dry state. J.Phys. Chem. 72, 1887-1889.

7. Bhat R and Ahluwalia JC (1985) Partial molar heat capacities and volumes of transfer of some amino acids and peptides from water to aqueous sodium chloride solutions at $298.15 \mathrm{~K}$. J. Phys. Chem. 89, 1099-1105.

8. Bondi A (1954) Free volumes and free rotation in simple liquids and liquid saturated hydrocarbons. J. Phys. Chem. 58, 929-939.

9. Bondi A (1964) Van der waals volumes and radii. J.Phys. Chem. 68, 441-451.

10. Feakins D, Freemantle DJ and Lawrence KG (1974) Transition state treatment of the relative viscosity of electrolytic solutions. Applications to aqueous, non-aqueous and methanol + water systems J. Chem. Soc., Faraday Trans. I. 70, 795-806.

11. Franks F, Quickenden MA, Reid DS, and Watson B (1970) Calorimetric and volumetric studies of dilute aqueous solutions of cyclic ethers derivatives. Trans. Faraday Soc. (66), 73, 582-589.

12. Franzosini $P$ and Edgar FW (1984) Thermophysics of metal alkanoates III. Heat capacities and thermodynamic properties of lithium and potassium propanoates J. Chem. Thermodyn. 16, 81-90.

13. Gurney RW (1953) Ionic Process in Solution; McGraw Hill. Vol.3, Chapter1.

14. Hakin AW, Duke MM, Marty JL and Preuss KEJ (1994a) Apparent molar heat capacities and volumes of some aqueous solutions of aliphatic amino acids at 288.15, 298.15, 313.15, and 328.15. K. J. Chem. Soc. Faraday Trans. 362- 368.

15. Hakin AW, Duke MM, Groft LL, Marty JL and Rashfeldt ML (1994b) Apparent molar heat capacities and volumes of some aqueous solutions of aliphatic amino acids at 288.15, 298.15, 313.15, and 328.15 K. Can. J . Chem. 72, 362-368.

16. Hedwig GR, Reading JF and Lilley TH (1991) Aqueous solutions containing amino acids and peptides. Part 27.-Partial molar heat capacities and partial molar volumes of some $\mathrm{N}$-acetyl amino acid amides, some $\mathrm{N}$-acetyl peptide amides and two peptides at $25^{\circ} \mathrm{C}$. J. Chem. Soc. Faraday Trans. 87, 1751-1758. 
17. Jones $G$ and Dole D (1929) The viscosity of aqueous solutions of strong electrolytes with special reference to barium chloride. J. Am. Chem. Soc. 51, 2950-2964.

18. Kharakoz DP (1991) Volumetric properties of proteins and their analogues in diluted water solutions. 2. Partial adiabatic compressibilities of amino acids at $15-70^{\circ} \mathrm{C}$. J.Phy.Chem. 95, 5634-5642

19. Li X, Ding C and Liu R (2006) Transfer volumes of glycine, L-alanine and L-serine from water to 1,2-butanediol-water mixtures at 298.15K. J. Soln. Chem. 35, 191-200.

20. Masson DO (1929) lon-solvent interactions. Philos. Mag. 8, 218-223.

21. Millero FJ, Surdo AL and Shin C (1978) The apprent molal and adiabatic compressibilities of aqueous amino acids at $25^{\circ} \mathrm{C}$. J.Phys.Chem. 82, 784-792.

22. Mishra AK and Ahluwalia JC (1981) Enthalpies, heat capacities and apparent molal volumes of transfer of some amino acids from water to aqueous t-butanol. $J$. Chem. Soc. Faraday Trans. 1. 77, 1469-1483.

23. Munde MM and Kishore N (2003) Volumetric properties of aqueous 2-chloroethanol solutions and volumes of transfer of some amino acids and peptides from water to aqueous 2-chloroethanol solutions. J. Soln. Chem. 32, 791-802.

24. Natarajan M, Wadi RK and Gour HC (1990) Apparent molar volumes and viscosities of some $\alpha$ - and $\alpha, \omega$-amino acids in aqueous ammonium chloride solutions at $298.15 \mathrm{~K}$. J. Chem.Eng. Data. 35, 87-93.

25. Owaga T, Mizutani K and Yasuda M (1984) The volume, adiabatic compressibility and viscosity of amino acids in aqueous alkali chloride solutions. Bull. Chem. Soc. Jpn. 57, 2064-2068.

26. Pandey JD, Mishra K, Shukla A, Mushran V and Rai RD (1987) Apparent molal volume, apparent molal compressibility, verification of jones-dole equation and thermodynamic studies of aqueous urea and its derivative. Thermochim. Acta. 117, 245-259.

27. Romero CM, Moren E and Rojas JL (1999) Apparent molal volumes and viscosities of DL$\alpha$-alanine in water-alcohol mixtures. Thermochim.Acta. 328, 33-38.

28. Roy MN, Sinha A and Sinha B (2005) Excess molar volumes, Viscosity deviations and isentropic compressibility of binary mixtures containing 1,3-dioxolane and monoalcohols at 303.15K. J. Solution Chem. 34, 1311-1325.

29. Roy MN, Sinha B, Dey R and Sinha A (2005) Solute-solvent and solute- solute interactions of resorcinol in mixed 1,4- dioxane-water systems at different temperatures. Int. J. Thermophys. 26, 1549-1563.

30. Roy MN, Sinha B and Dakua V (2006) Excess molar volumes and viscosity deviations of binary liquid mixtures of 1,3-dioxolane and 1,4dioxane with butyl acetate, butyric acid, butyl amine and 2-butanone at 298.15K. J. Chem. Eng. Data. 51, 590-594.

31. Wadi RK and P.Ramasmi (1997) Partial molal volumes and adiabatic compressibilities of transfer of glycine and DL-alanine from water to aqueous sodium sulphate at 288.15, 298.15, and 308.15K. J.Chem.Soc. Faraday Trans. 93(2), 243-247. 